\title{
The Effectiveness of Hedge Fund Investment Strategies under Various Market Conditions Michał Falkowski ${ }^{1}$, Agata Sierpińska-Sawicz ${ }^{2}$ and Piotr Szczepankowski ${ }^{3}$
}

ABSTRACT

\begin{abstract}
The main purpose of the article was to analyze the effectiveness of the basic investment strategies used by hedge funds in the long term (years 1994-2015) and during the global financial crisis (years 2007-2009). Using information from commercial databases we attempted to verify the hypothesis that alternative hedge funds, regardless of the type of strategy they use, are capable of achieving better outcomes than other capital allocation options, at any time and under a variety of market conditions. We analyzed hedge funds effectiveness in two stages. For stage one, we performed a profitability analysis for the whole hedge funds sector in the two periods and compared the results with the stock rates of return achieved by investors in the global market for the same period and with the risk-free rate. At stage two we calculated ratios that included rate of return and risk, though only for specific strategies. We used traditional portfolio performance measures (Sharpe, Treynor, Jensen ratios) as well as the newer ones (the Sortino ratio, downside deviation). The results show no confirmation that investments carried out by hedge funds are more risky than traditional capital investment methods. Risk associated with investments by the analyzed entities was lower not only in times of prosperity, but also during crisis, providing a clear indication of the higher effectiveness of entities operating in the alternative investment sector and regardless of the changes taking place in the financial market, the length of the capital investment period or the investment strategy being pursued.
\end{abstract}

KEY WORDS: $\quad$ hedge funds, efficiency, investment strategies, financial crisis

JEL Classification: G01, G20, G23, G32.

Deutsche Bank, United Kingdom

2Poznań University of Economics, Poland

${ }^{3}$ University of Economics and Human Sciences in Warsaw, Poland

\section{Introduction}

The primary objective of any investment fund is to produce a long-term increase in the value of its assets, by achieving rates of return that exceed the inflation rate, the profitability of other funds that manage similar portfolios, and the market risk (Jaeger, 2003). The operation of hedge funds (HFs), however, does not focus on achieving a high relative rate of return, as is the case for traditional funds, but rather on achieving a high absolute return. This is because HFs do not try to "beat" any kind of a benchmark, working instead to make a profit regardless of the

Correspondence concerning this article should be addressed to: Agata Sierpińska-Sawicz, Poznań University of Economics. E-mail: agata.sierpinska-sawicz@ue.poznan.pl current market conditions (Schneeweis \& Martin, 2001). By actively managing capital, HFs are able to exploit market inefficiencies, arbitrage opportunities in local markets, and any available information (Giraud et al., 2001). They also structure their investment portfolios in a way adjusted to changing market conditions (Lhabitant, 2006).

Hence, the main purpose of our study was to analyze the effectiveness of the basic investment strategies used by HFs in the long term, including the period of the global financial crisis. In our analysis, we sought evidence for the thesis that alternative funds, regardless of the type of strategies they use, are capable of achieving better outcomes than other capital allocation options, at any time and under a variety of market conditions. 


\section{Hedge Fund Effectiveness Evaluation in Literature}

In the previous century, the transparency of $\mathrm{HF}$ operation was poor. HFs took advantage of the lack of disclosure requirements, and refrained from reporting many types of information publicly, including that on their investment performance. Therefore, any sound evaluation of their operations was difficult. New regulations introduced in the first decade of the 21st century imposed reporting obligations on HFs, which significantly facilitated collecting information on their activities. This does not, however, imply that complete data is available, due to factors such as diversity of existing funds, as well as difficulties in associating funds with specific investment strategies and in determining the share of each entity in the market indexes of their respective sectors.

Due to such incomplete information on the activity of HFs, literature on the subject focuses on threats, rather than benefits, associated with their operation. Authors point out, for instance, that in aiming at high returns, funds may conduct their investments in an unethical manner, generating excessive risk to the financial system. As to the positive aspects of HFs, it is argued that their operation and their higher investment risk helps maintain liquidity on the market, cushioning the effects of market shocks. According to another well-established view, the presence of HFs, as entities actively accumulating risk, contributes to the development of emerging markets and specialized overthe-counter markets (e.g. derivatives). Additionally, as they strive for above-average returns, HFs' use of arbitrage neutralizes differences between different markets in prices for the same kind of risk premium. HFs are also believed to enable investment portfolio diversification, complementing the market offer.

Number of authors have discussed the issue of HFs' effectiveness. Joenväärä et al. (2012) analyzed these funds' performance using five commercial databases. Their findings were consistent with those from previous analyses (Kosowski et al., 2007), demonstrating that HFs provide investors with absolute returns, regardless of the size of the fund, its location, markets it is active in, or type of investment strategies implemented.

Beside the exact rate of return, it is also interesting to see how consistent (repeatable) HF performance is. Some studies show it is guaranteed for a 12-month horizon (Jagannathan et al., 2010; Kosowski et al., 2007). Other studies, in turn, demonstrated that HF performance may be repeated on a quarterly basis (Agarwal \& Naik, 2000; Brown et al., 1999; Liang, 2000). Recently, however, researchers confirmed that periods for which HFs are capable of producing consistent, stable, and sustainable returns tend to be longer (Joenväärä et al., 2012).

Another subject that is discussed in literature is HFs' impact on financial stability. Though evidence exists to confirm that any negative event on financial markets may affect the effectiveness of HFs, there are no clear indications that they are the only entities that cause market instability. Capital redemption and asset illiquidity do have an adverse impact on the performance of specific HFs, but there is no clear evidence of their responsibility in this respect (Boyson et al., 2010; Getmansky, et al., 2004;). Empirical data so far indicate rather that HFs decrease instability and alleviate systemic risk, primarily due to the anti-cyclical nature of their investments. By taking positions contrary to market trends, they ensure diversified market response to any adverse events (Brunnermeier \& Nagel, 2004).

Regulatory changes on the market have significantly improved risk management infrastructure in the HF sector, which is relevant to the evaluation of their effectiveness. Though changes in risk management standards are believed by some to have increased funds' operating costs, thus reducing their rates of return, better risk management has been demonstrated to increase the effectiveness of fund operation. Cassar and Gerakos (2013) studied the effectiveness of investment portfolio risk management methods used by HF managers. Their analysis of selected entities demonstrated that funds using adequate risk management instruments perform better during financial market declines, and have less risk exposure. In particular, entities that use the value-at-risk model and stress-tests achieve more stable returns on their investments, even during sharp drops in asset values on the market. Research shows that risk control methods used by funds significantly improve their performance in the long term, reduce the number of failed investments, and curb the risk of insolvency (Brown et al., 2012).

Empirical analyses of HF investment activities 
also demonstrate that their effectiveness results from short selling, which increases the liquidity of financial instruments and assists in asset valuation on the market (Beber \& Pagano, 2013; Marsh \& Payne, 2010). Another important issue in studies on HF effectiveness is the extent of interest in these funds among institutional investors, which is thought to indicate the importance of these entities for financial markets, as well as to demonstrate the funds' need for sustainable investment strategies. Institutional investors are increasingly willing to place their financial resources in HFs, knowing that these funds offer higher rates of return than other capital allocation options available on the market.

\section{Methods and Scope of the Study}

We analyzed HF effectiveness in two stages. In stage one, we performed a profitability analysis for the whole HF sector in two periods, including the long term (years 1994-2015) and the times of the global financial crisis (years 2007-2009). Using information from two databases, we calculated total, mean annual, and mean monthly rates of return for the entire study sample, and subsequently compared the results with the stock market rates of return for the same period, and with the risk-free rate. The global financial turmoil that has gripped the world economy since 2007 has been widely viewed as unprecedented, at least since the Great Depression of the 1930s. The turbulence in financial systems was followed by a significant reduction in real economic activity in a large number of countries. We understand the importance of including this period in the analysis of hedge fund's efficiency due to the fact that the global financial crisis heavily impacted major financial institutions including investment bank. As a result, through interdependent relation and contagion on the financial markets hedge funds could be impacted directly or indirectly.

Though HFs aim at obtaining absolute returns, risk associated with their investments cannot be disregarded in an effectiveness analysis. Thus, in second stage of the analysis, we used monthly data to calculate basic investment portfolio performance measures, considering return and risk, in the same periods, though only for specific strategies. Traditional portfolio performance measures (Sharpe, Treynor, and Jensen ratios) are based on the Capital Asset Pricing Model (CAPM) (Sharpe, 1966). Newer ones (the Sortino ratio and downside deviation) are variations of the former, developed through a critical approach, in particular to the Sharpe ratio (1966). This is due to the fact that the risk measure included in the ratio increases in line with deviation from the mean rate of return on the portfolio, even though only negative deviations are undesirable from the investors' perspective. Therefore, it seems more reasonable to only include deviations below the mean rate of return in the portfolio performance measurement, which is reflected in the Sortino ratio. Instead of risk-free rate of return, the calculation uses the minimum rate of return acceptable to the investor, and instead of standard deviation for return on the portfolio, it uses semi-deviation, or the so-called downside risk.

Another way of eliminating the limitations associated with using standard deviation is downside deviation (DD), which ignores all positive deviation and only includes results below the selected minimum acceptable rate of return. It can be set at zero, equal to the risk-free rate, or adjusted to the market mean.

We collected the source material for our HF strategy effectiveness analysis from the comprehensive hedge fund database by BarclayHedge $(\mathrm{BH})$. We used data for a period between the beginning of 1994 and the end of 2015, including results for nearly 5000 funds, available at the time of analysis. We based our performance measure calculations on monthly values, due to the available granularity of data on HFs. In order to ensure the validity of results for each fund, we set a required minimum of 12 consecutive monthly return values per fund.

Data in the $\mathrm{BH}$ database is organized using an internal, two-tiered classification of investment strategies, producing as many as 73 specific strategy types. To facilitate comparisons between these data and data from other sources, we used a simpler classification in the analysis, aggregating all strategies defined in the $\mathrm{BH}$ database into 12 categories.

No single approach to investments can be assigned to all HFs. A 2003 study by the Alternative Investment Management Association (AIMA) provided interesting insights on the investment styles of HFs. Half of the studied entities reported they used their own investment strategy classifi- 
cations, $47 \%$ stated they use one or more strategies described in literature on the subject, while the remaining ones believed their strategy could not be strictly defined. The investment strategies most commonly used by HFs are divided into directional, relative value (non-directional), evendriven, and hybrid strategies (Stefanini, 2006).

Directional strategies are the most popular. Within these strategies, HFs use a high degree of financial leverage, combining short and long positions for various assets whose prices move in the same direction as changes in the market (Hedges IV, 2005), and return on investment depends on the direction of these changes (Agarval \& Naik, 2000). Therefore, directional strategies typically have high variations in performance, especially in the short term. These strategies include: long/short equity, dedicated short bias, managed futures, global macro, and emerging markets (Lhabitant, 2006; Stefanini, 2006).

Another category comprises strategies based on relative value, also termed non-directional strategies. These strategies involve investments independent of any market trends, based on the identification of differences in valuation of related instruments, and opening opposite positions to neutralize risk. This strategy group includes: convertible arbitrage, fixed income arbitrage, equity market neutral (Lhabitant, 2006; Nicholas, 2000).

Event-driven strategies aim at profiting by focusing investment activities on opportunities presented by exceptional situations (events) occurring at the issuers', affecting asset values. The uncertainty of an event creates an opportunity for profiting by allocating capital in the issuer's assets at the right moment. This strategy category includes distressed securities and merger arbitrage strategies as main examples. Both strategies may offer high absolute return, but they entail significant risk.

The final category comprises hybrid strategies, combining the major advantages of specific strategies discussed above. Such approaches are used by those entities who consider the market as global, and focus on assets for which buyers can be found anywhere. This category mainly includes multistrategy investing, or allocating capital using a combination of strategies, and FoHF, i.e. allocating capital in the assets of other HFs. By provid- ing investment diversification, these strategies allow the funds to achieve positive returns regardless of the direction of price changes in markets.

The studied sample ultimately included 3364 entities (no entity overlap in the examined data set). 1189 entities were not included in any category due to insufficient information, large diversity of strategies used, or in the case of some entities, operation as FoHFs. We also excluded 211 funds that did not meet the required minimum of 12 consecutive observations. 190 hedge funds ceased to exist during the 19 year period. Table 1 shows the basic attributes of the studied sample.

It is important to note that hedge funds report to databases on a voluntary basis. Thus, systemic risk measures can potentially suffer from several biases. We minimize survivorship bias by using post-1994 data, which comprise both active and defunct funds. Fung and Hsieh (2006) report that hedge fund data suffer from liquidation bias that refers to the fact that hedge fund managers stop reporting returns to a database prior to the possible final liquidation value of a fund. In addition, systemic risk measures may also suffer from backfilling bias and self-selection bias. When new funds enter the database, their prior track record is backfilled into the database, while self-selection bias may arise as only funds with good performance choose to market their performance via data vendors.

We also obtained supporting data from the following sources:

1. The Credit Suisse/Tremont database, aggregating information on a number of funds similar to that included in the $\mathrm{BH}$ database, including only funds managing portfolios valued at USD 50 million or more. All entities included in the database have operated for more than 12 months, as results for the first year of a fund's operation are not included in the calculation of its HF index (CSHFI). Another premise of the database is that the CSHFI index represents at least $90 \%$ of total assets of the HFs in operation. CSHFI data reach back to 1994 . Therefore, by using these data, we were able to investigate long-term fund performance in more detail, and to compare these results with those obtained from the $\mathrm{BH}$ database.

2. The Morgan Stanley Capital International (MSCI) database, from which we obtained historical values of the global stock market index (MSCI World 
Table 1. Investment Strategy Groups, Number of Funds in Each Group, and Mean Annual Value of Managed Assets (in USD)

\begin{tabular}{|c|c|c|}
\hline Strategies & Number of funds & $\begin{array}{c}\text { Mean annual value of managed } \\
\text { assets }\end{array}$ \\
\hline
\end{tabular}

\section{DIRECTIONAL}

Long/short equity

Dedicated short bias

Managed futures

Global macro

Emerging markets

\section{NON-DIRECTIONAL}

Convertible arbitrage

Fixed income arbitrage

\section{EVENT-DRIVEN}

Distressed securities

Event driven

\section{HYBRID}

Index). In our study, this index was used as a benchmark for the HF sector index, and as an additional reference for the investment strategy effectiveness analysis. We also included the S\&P500 stock market index, against which the BHFI index representing HF performance was compared.
3. The US Department of the Treasury, from which we obtained data regarding the yield on short-term (three-month) US treasury bills. We used the yield on treasury bills as a risk-free rate of return, against which the performance of specific strategies and the entire HF sector was compared. We also used mean 
treasury bill yield as the minimum acceptable return (MAR) in Sortino ratio and DD calculations.

Notably, due to frequent shortcomings in the transparency of information provided by HFs to commercial databases, the data is not free from bias. When analyzing HF data, one must consider two types of bias, namely, survivorship bias and selfselection bias (Perez, 2011). Survivorship bias exists when analysis only includes information on active funds. To eliminate this bias, we used data for a period starting in 1994, as this data set includes information on both active and defunct entities. In turn, self-selection bias results from the non-public nature of HFs and the limited transparency of their activities, compared to traditional funds. In consequence, the rates of return reported to databases are likely to be higher than those actually achieved. However, a study by Edelman, et al. (2013) demonstrated that the self-selection biased identified in commercial databases is negligible, as the reported higher- and lower-than-actual rates of return cancel each other out. Still, it is important to bear in mind that databases are not always free from error or bias, which may result, among other factors, from the large diversity of HFs, insufficient numbers of funds included in a database, ambiguity regarding the classification of a fund's investment strategies, or difficulties in assigning weights to funds included in an index. Our preliminary evaluation of the data collected for the present analysis clearly indicated that the data were valid and that the analyzed entities formed a representative sample.

\section{Analysis of HF Performance Under Various Market Conditions}

At the first stage of the study, we analyzed the profitability of investments by all the studied HFs. Using information on the BHFI index, published since 1997, we calculated annual rates of return for the HF sector until the end of the studied period (Figure 1). The funds' performance depended on their ability to take advantage of asset price variations in the global financial market and its specific segments. Throughout the analyzed period, HFs only had a negative performance twice. The largest loss in the sector occurred in 2008, and was associated with the global financial crisis, as well as with the internal structure of the funds, most of which used directional investment strategies. With a high exposure to equity-based instruments, the funds comprised in this group were also largely associated with the negative value of the BHFI in 2011, during global economic slowdown.

Historical data indicate that at the end of the analyzed long term, the total HF rate of return was twice as high as that of the share market, reflected by the S\&P500 index (Figure 2).

Actively managed funds, including HFs, may achieve higher-than-market rates of return if most of their investment decisions turn out to be accurate, despite the random nature of asset price changes in the market. This occurs when HF portfolio managers identify and successfully use "inefficiencies", as was the case throughout the analyzed period. Notably, however, such opportunities are not long lasting, one reason for which is the increasing efficiency of contemporary financial markets.

Our analysis of HF returns during and after the 2007-2009 financial crisis demonstrates that these types of entities are no longer viewed only as institutions that offer high absolute return to investors. They are increasingly seen as entities that may secure investment portfolios, though they continue to outperform other financial instruments. In 2015 (Table 2), when HFs had the poorest performance after 2011, their return was positive, though low, and still higher than that from investments in other markets (stock, bond, or commodity).

The main reason for the better investment performance of HF, compared with traditional forms of capital allocation, is the value of the correlation coefficient for rates of return on investment in HFs and in the market portfolio of stocks (Table 3). The correlation coefficients also indicate that investment in funds secured the investor against excessive losses during stock market declines.

Other data included in our analysis indicate that other HF sector indices, beside BHFI, had a similar course in the long term. Some differences are, however, notable. The CSHFI (which is an index published for a slightly longer period than the BHFI) showed more stable rises and gentler falls compared to the global stock market index (MSCI). Funds included in the CSHFI produced long-term profits 


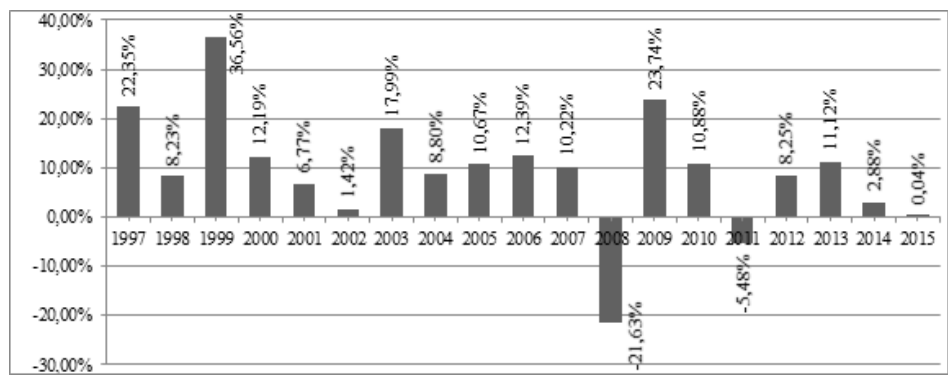

Figure 1. HFs' annual rates of return in the years 1997-2015.

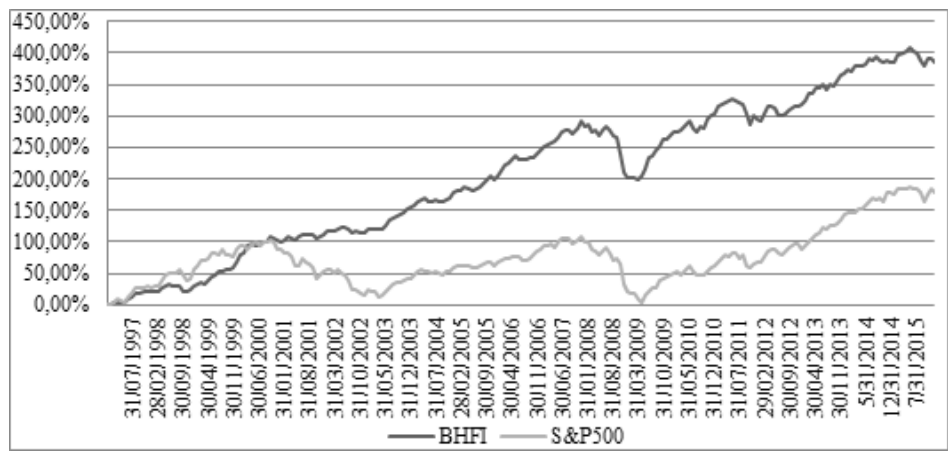

Figure 2. BHFI and S\&P500 in the years 1997-2015 (\%). 
Table 2. Hedge Fund Performance in 2015 Compared Against Other Market Segments

\begin{tabular}{lc}
\hline Index & Rate of return (\%) \\
\hline BHFI & 0.04 \\
S\&P500 & -0.73 \\
S\&PGSCI & -32.86 \\
MSCI World & -2.74 \\
MSCI EAFE & -3.30 \\
MSCI Emerging Markets & -16.96 \\
Barclays Capital Global Aggregate Bond Index & -3.15 \\
Barclays High Yield Index
\end{tabular}

Table 3. Pearson's Correlation Coefficient Matrix for Rates of Return on the BHFI, S\&P500, and MSCI Indices (Years 1997-2015)

\begin{tabular}{lccc}
\hline & BHFI & S\&P500 & MSCI \\
\hline BHFI & 1.00 & & \\
S\&P500 & 0.68 & 1.00 & 1.00
\end{tabular}

which, contrary to stock investments, were resistant to stock price drops seen during the 2000-2002 downturn that resulted from the so-called dot-com bubble burst. As to falls related to the 2007-2009 financial crisis, they were considerably lower, as Figure 3 demonstrates.

Over the entire studied period, the total rate of return was $191 \%$ for the MSCI, and $450 \%$ for the CSHFI. These findings confirm our hypothesis that HFs achieve significantly higher profitability regardless of current market conditions, and their investments carry less risk than direct allocation of capital in stocks. Measures shown in table 6 are consistent with the finding. Between January 1994 and December 2015, the mean monthly rate of return in the fund market was $0.67 \%$, while the mean monthly rate of return in the global stock market was $0.50 \%$. In the same period, mean monthly risk-free rate of return was $0.32 \%$.

This higher profitability of HFs is demonstrated even more clearly by a comparison of maximum and minimum monthly rates of return in the analyzed period. For both HF indices, the largest monthly loss was approx. $7.5 \%$, and the highest profit was approx. $8.5 \%$, while the global stock market index was at a $19.05 \%$ loss in the poorest month, and turned a $10.91 \%$ profit in the best month.

Our analysis of historical return variation also indicates that the average investor would benefit from choosing 


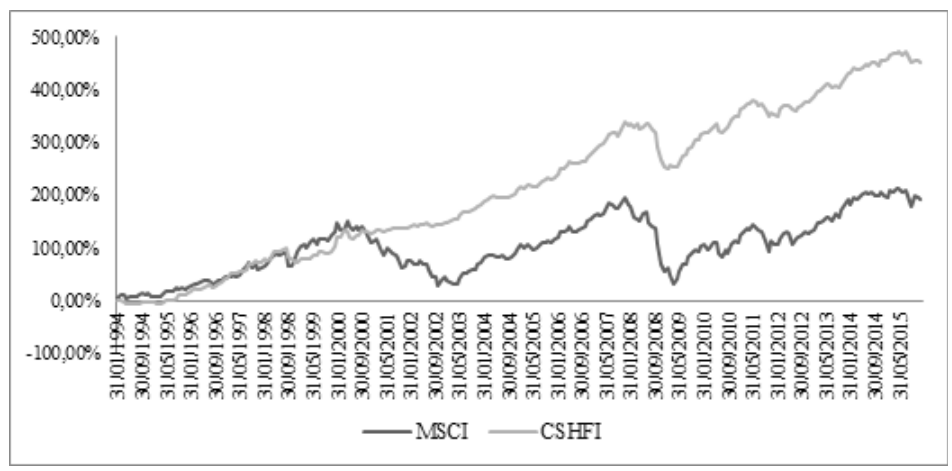

Figure 3. CSHFI and MSCI performance in the years 1994-2015.

HF portfolios. Risk, measured by the standard deviation of monthly rates of return, was more than $50 \%$ lower for the HF sector than for the stock market. Moreover, for the HF sector, with its higher return and lower risk, the DD variation coefficient was more than two times lower than for the global stock market. Similar conclusions can also be drawn based on the DD itself, which was between $1.52 \%$ and $1.65 \%$ for the monthly HF rates of return, and more than twice that for the stock market rates of return. This means that at times when the rate of return on the analyzed indices was lower than the MAR (risk-free rate), the mean deviation of HF performance was half that of the stock market performance.

Our $\beta$ calculation results also confirm the lower risk associated with HF investments. Its value (between 0.28 and 0.35 , depending on the index) shows that HF returns are weakly correlated with the market, which may indicate the positive characteristics of their investment portfolios resulting from skillful diversification of assets by HF managers. The correlation between the indices is also notable. Pearson's correlation coefficient shows a moderately strong, positive interrelation of the analyzed indices.

The observed superior performance of HFs in the long term is also reflected in data for the financial crisis period, namely, between June 2007 and February 2009. Mean monthly losses of funds in that period were small compared to those sustained in the global stock market (Figure 4 and Table 5). Results for the crisis period show that at a time when asset prices in the global market fell, HFs were able to protect a large portion of the capital entrusted to them, though their performance reflected in the indices for the sector does not fully match the premise of these funds, as they did not achieve returns higher than the acceptable minimum (risk-free rate). They did, however, sustain smaller losses than those seen in the global stock market. Regarding extreme values, the maximum monthly loss in the stock market was $19.05 \%$, twice as high as that observed in the HF sector. The highest monthly rate of return for the stock market during the crisis was $4.98 \%$, approx. 1.5 pp higher than for the HF sector. Considering that the markets were in decline at the time, the observed change in the correlation coefficient for rates of return in the HF sector and stock market should be considered contrary to the overall premise of these types of funds. The correlation coefficient indicates that the interrelation between the performance of HF managers and the global economic conditions was weaker 
Table 4. Selected Measures for the Analyzed Indices in the Long Term (1994-2015)

\begin{tabular}{|c|c|c|c|c|}
\hline Parameter & BHFI $^{*}$ & CSHFI & MSCI & 3M US T-Bills \\
\hline Total rate of return & $398.36 \%$ & $450.00 \%$ & $190.96 \%$ & $77.55 \%$ \\
\hline $\begin{array}{l}\text { Mean monthly rate } \\
\text { of return }\end{array}$ & $0.76 \%$ & $0.67 \%$ & $0.50 \%$ & $0.32 \%$ \\
\hline $\begin{array}{l}\text { Minimum monthly } \\
\text { rate of return }\end{array}$ & $-7.73 \%$ & $-7.55 \%$ & $-19.05 \%$ & $0.00 \%$ \\
\hline $\begin{array}{l}\text { Maximum monthly } \\
\text { rate of return }\end{array}$ & $8.41 \%$ & $8.53 \%$ & $10.91 \%$ & $0.53 \%$ \\
\hline $\begin{array}{l}\text { Standard deviation } \\
\text { of the rate of return }\end{array}$ & $2.08 \%$ & $2.03 \%$ & $4.32 \%$ & $0.15 \%$ \\
\hline $\begin{array}{l}\text { Downside deviation } \\
\text { (DD) }\end{array}$ & $1.65 \%$ & $1.52 \%$ & $3.34 \%$ & $0.02 \%$ \\
\hline $\begin{array}{l}\text { DD variation coef- } \\
\text { ficient }\end{array}$ & 2.31 & 2.28 & 6.69 & 0.05 \\
\hline$\beta$ & 0.35 & 0.28 & 1.00 & - \\
\hline $\begin{array}{l}\text { Pearson's correlation } \\
\text { coefficient }\end{array}$ & 0.59 & 0.60 & 1.00 & 0.15 \\
\hline
\end{tabular}

than in the long term. During the crisis, as stock prices fell, so did the value of assets managed by HFs, which is likely strictly associated with the funds' predominant use of directional investment strategies.

\section{The Effectiveness of Hedge Fund Investment Strategies}

We analyzed the performance of individual investment strategies used by HFs over two periods: long-term (Table 6) and during the global financial crisis (Table 7). In the long term, the analyzed strategies and strategy groups seem to be effective. With the exception of one directional strategy, all strategies achieved positive total rates of return, exceeding returns on both riskfree assets and the global stock portfolio. Mean annual and monthly results are slightly less optimistic, as some non-directional strategies performed worse than investments in the stock market. Hence, this strategy category may be viewed as the least effective for HFs in the long term. Event-driven and hybrid strategies may be considered effective on a par with directional strategies. Though returns achieved using these strategies were slightly lower than with directional ones, the associated investment risk was lower as well.

In the directional strategy group, two strategies had the highest returns and the best performance measure values, global macro and long/short equity. The former yielded the highest mean monthly rate of return of all analyzed strategies, at the lowest risk level, in the study period. This supports the view that global macro funds make profitable and safe investments that are largely independent of 
Table 5. Selected Measures for the Analyzed Indices During the Financial Crisis (June 2007-February 2009)

\begin{tabular}{|c|c|c|c|c|}
\hline Parameter & BHFI & CSHFI & MSCI & 3M US T-Bills \\
\hline Total rate of return & $-2.64 \%$ & $-1.44 \%$ & $-50.41 \%$ & $4.13 \%$ \\
\hline $\begin{array}{l}\text { Mean monthly rate } \\
\text { of return }\end{array}$ & $-0.82 \%$ & $-0.02 \%$ & $-1.83 \%$ & $0.18 \%$ \\
\hline $\begin{array}{l}\text { Minimum monthly } \\
\text { rate of return }\end{array}$ & $-8.41 \%$ & $-6.55 \%$ & $-19.05 \%$ & 0.00 \\
\hline $\begin{array}{l}\text { Maximum monthly } \\
\text { rate of return }\end{array}$ & $3.62 \%$ & $3.16 \%$ & $4.98 \%$ & $0.41 \%$ \\
\hline $\begin{array}{l}\text { Standard deviation } \\
\text { of the rate of return }\end{array}$ & $2.96 \%$ & $2.25 \%$ & $5.37 \%$ & $0.14 \%$ \\
\hline $\begin{array}{l}\text { Downside deviation } \\
\text { (DD) }\end{array}$ & $2.52 \%$ & $0.73 \%$ & $2.07 \%$ & $0.02 \%$ \\
\hline $\begin{array}{l}\text { DD variation coef- } \\
\text { ficient }\end{array}$ & -140.74 & -146.07 & -2.94 & 73.56 \\
\hline$\beta$ & 0.35 & 0.29 & 1.00 & - \\
\hline $\begin{array}{l}\text { Pearson's correlation } \\
\text { coefficient }\end{array}$ & 0.36 & 0.30 & 1.00 & 0.49 \\
\hline
\end{tabular}

the current conditions in the traditional financial instrument market. On the other hand, strong focus on that market is typical for another strategy in this group, long/short equity. In its case, risk was higher, which resulted in worse monthly performance of these portfolios, compared with global macro.

We obtained a more reliable evaluation by comparing the effectiveness of each strategy against a benchmark, provided by an HF sector index (CSHFI). In this analysis, the two directional strategies, global macro and long/short equity, are still above average. With regard to risk measured by DD, beside the riskfree investment, merger arbitrage and multistrategy funds had risk levels below that established for the entire sector, while equity market neutral, emerging markets, and dedicated short bias funds had the highest risk levels. By including performance measures, we could decisively identify strategy effectiveness in the long term. The most effective strategy was the directional global macro strategy. The event-driven distressed securities strategy also performed better than the sector in total. The least effective strategies, compared to the entire sector, were dedicated short bias and equity market neutral.

We obtained some supporting findings by including the $\beta$ factor in the analysis. We found negative beta values for two directional strategies, namely dedicated short bias and managed futures, which indicates that these strategies were not effective. Other strategies in the same group can be considered aggressive, while strategies in the remaining groups were less strongly associated with the overall market 


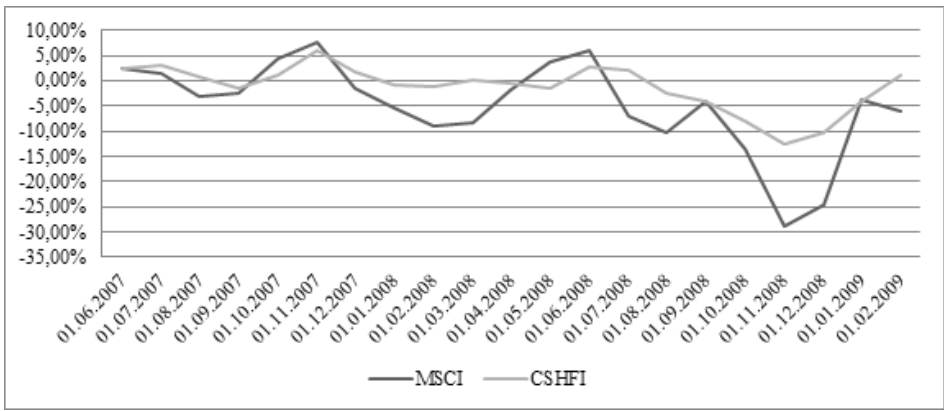

Figure 4. CSHFI and MSCI performance during the financial crisis.

trends, and can therefore be considered defensive.

Our analysis clearly indicates that in the long term, directional, event-driven and hybrid strategies are the most effective for HFs. All these strategies perform better than the HF sector overall, and than investments in the global stock market. Non-directional strategies were clearly the least effective in the long term.

As to the effectiveness of HF investment strategies during the global financial crisis, it is notable that one directional strategy, dedicated short bias, which we found the least effective in the long term, provided the highest positive rates of return in the crisis period. Managed futures funds yielded the second largest rate of return during this period, while the remaining strategies (except for global macro and merger arbitrage) had returns below the risk-free rate. We should bear in mind that fulfilling the definition of an HF, i.e. turning a profit despite falling asset prices in the market, depends on the exact strategy used, and is not a characteristic of the entire sector. As in the long term, also in the times of crisis, directional and event-driven strategies were the most effective, and non-directional strategies - the least effective. Though more than half of the analyzed HF investment strategies performed better than the sector benchmark during the crisis, which indicates effective portfolio management, only some of these strategies had positive measure values. Using variation analysis, we identified strategies for which overall risk was lower than that for the benchmark CSHFI index. This group included some directional and eventdriven strategies, as well as multistrategy funds. To answer the question about the most effective investment strategy during the financial crisis, we needed to compare the obtained results against the commonly accepted criteria for HFs. The market conditions during the global financial crisis were another consideration in this assessment. Considering both criteria, we found that managed futures was clearly the most effective strategy during crisis. While prices in the global stock market dropped by more than $50 \%$, this strategy allowed for increasing the value of invested capital by nearly $30 \%$. The associated risk, reflected by beta, was among the lowest for all the analyzed indices. We found a similar, though slightly lower, effectiveness for the dedicated short bias strategy. Though its total rate of return during the crisis was high, its variation was larger than that for the entire HF sector. Global macro and merger arbitrage also merit attention. In this case, the rates of return achieved under difficult market conditions are explained by an investment policy involving a broad spectrum of various financial instruments, which allows for profiting even as asset prices fall in the 
Table 6. Performance Measures for HF Investment Strategies in the Long Term (1994-2015)

\begin{tabular}{|c|c|c|c|c|c|c|c|c|c|c|c|c|}
\hline & 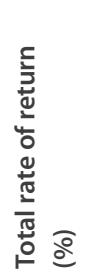 & 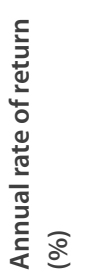 & 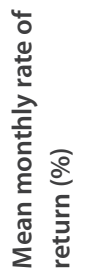 & 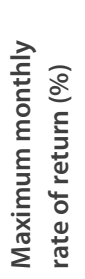 & 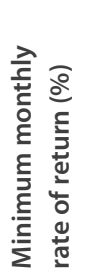 & 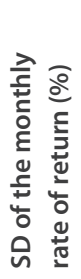 & $\stackrel{\Xi}{\mathscr{D}}$ & $\begin{array}{l}\frac{0}{0} \\
\frac{1}{0} \\
\frac{0}{0} \\
\frac{0}{0} \\
\frac{\pi}{n} \\
\text { n. }\end{array}$ & 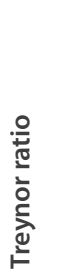 & 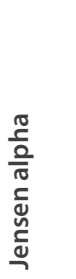 & 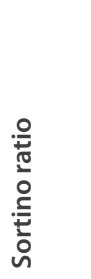 & $\frac{\grave{\varrho}}{\stackrel{0}{0}}$ \\
\hline 3M US T-Bills & 78 & 3.91 & 0.32 & 0.53 & 0.00 & 0.15 & - & 0.00 & 0.00 & - & - & 0.02 \\
\hline $\mathrm{MSCl}$ & 191 & 6.17 & 0.50 & 10.91 & -19.05 & 4.32 & 1.000 & 0.04 & 0.18 & - & - & 3.34 \\
\hline CSHFI & 450 & 8.34 & 0.67 & 8.53 & -7.55 & 2.03 & 0.281 & 0.17 & 1.25 & 0.62 & 0.012 & 1.52 \\
\hline \multicolumn{13}{|c|}{ DIRECTIONAL STRATEGIES } \\
\hline $\begin{array}{l}\text { Global } \\
\text { macro }\end{array}$ & 785 & 10.82 & 0.86 & 10.60 & -11.55 & 2.61 & 0.142 & 0.21 & 3.80 & 0.51 & 0.060 & 1.98 \\
\hline $\begin{array}{l}\text { Long/short } \\
\text { equity }\end{array}$ & 578 & 9.51 & 0.76 & 13.01 & -11.43 & 2.67 & 0.440 & 0.17 & 1.23 & 0.36 & 0.017 & 1.87 \\
\hline $\begin{array}{l}\text { Emerging } \\
\text { markets }\end{array}$ & 334 & 7.83 & 0.63 & 16.42 & -23.03 & 3.97 & 0.549 & 0.08 & 0.56 & 0.22 & 0.012 & 3.28 \\
\hline $\begin{array}{l}\text { Dedicated } \\
\text { short bias }\end{array}$ & -69 & -11.25 & -0.33 & 22.71 & -11.28 & 4.68 & -0.802 & -0.14 & 0.81 & -0.51 & 0.004 & 2.50 \\
\hline $\begin{array}{l}\text { Managed } \\
\text { futures }\end{array}$ & 217 & 6.04 & 0.49 & 9.95 & -9.35 & 3.33 & -0.020 & 0.05 & -8.50 & 0.17 & -0.354 & 1.94 \\
\hline
\end{tabular}

NON-DIRECTIONAL STRATEGIES

\begin{tabular}{|c|c|c|c|c|c|c|c|c|c|c|c|c|}
\hline $\begin{array}{l}\text { Equity mar- } \\
\text { ket neutral }\end{array}$ & 169 & 5.16 & 0.42 & 3.66 & -40.45 & 2.75 & 0.184 & 0.04 & 0.54 & 0.07 & 0.023 & 4.10 \\
\hline $\begin{array}{l}\text { Fixed } \\
\text { income } \\
\text { arbitrage }\end{array}$ & 203 & 5.28 & 0.43 & 4.33 & -14.04 & 1.52 & 0.133 & 0.07 & 0.83 & 0.09 & 0.032 & 2.01 \\
\hline $\begin{array}{l}\text { Convertible } \\
\text { arbitrage }\end{array}$ & 315 & 6.80 & 0.55 & 5.81 & -12.59 & 1.86 & 0.180 & 0.13 & 1.28 & 0.20 & 0.031 & 1.99 \\
\hline
\end{tabular}


Table 6. Performance Measures for HF Investment Strategies in theLong Term (1994-2015) (Continued)

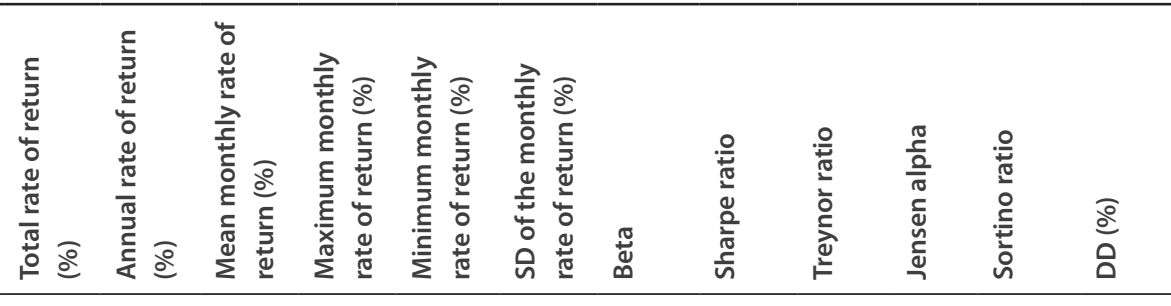

EVENT-DRIVEN STRATEGIES

\begin{tabular}{|c|c|c|c|c|c|c|c|c|c|c|c|}
\hline $\begin{array}{l}\text { Distressed } \\
\text { securities }\end{array}$ & 628 & 9.51 & 0.76 & 4.15 & -12.45 & 1.81 & 0.268 & 0.25 & 1.64 & 0.40 & 0.029 \\
\hline Event driven & 493 & 8.60 & 0.69 & 4.22 & -11.77 & 1.77 & 0.278 & 0.21 & 1.33 & 0.32 & 0.025 \\
\hline $\begin{array}{l}\text { Merger arbi- } \\
\text { trage }\end{array}$ & 246 & 5.79 & 0.47 & 3.81 & -6.15 & 1.16 & 0.145 & 0.13 & 1.03 & 0.13 & 0.033 \\
\hline
\end{tabular}

HYBRID STRATEGIES

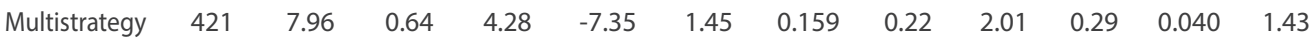

market. Funds using strategies other than those listed above were not able to turn a profit during the crisis. Though some of these strategies (e.g. multistrategy) had a better return-to-risk ratio than the sector overall, they produced returns lower than the riskfree rate, and cannot therefore be considered effective.

\section{Conclusions}

Findings from our analysis warrant several general conclusions regarding HF activities. By analyzing the collected data, we identified changes in HF performance under various conditions, including periods of disturbance in financial markets. Our analyses indicate that these entities make effective investments regardless of market conditions. Both in the long term and during the 2007-2009 crisis, the overall performance of the study sample was better than that of the global stock portfolio. Furthermore, HF asset values had a significantly lower variation than that seen in the stock market, misrepresenting the claim that investing capital in HFs entails a high level of risk. Risk associated with investments by the analyzed entities was lower, not only in times of prosperity, but also during crisis, providing a clear indication of the higher effectiveness of entities operating in the alternative investment sector.

With regard to specific strategies, we found that most analyzed strategies were effective in the long term, in all the evaluated aspects, which strongly indicates that HFs are capable of effectively managing various asset portfolios. The best results are provided by strategies involving investments in various markets, using arbitrage opportunities, and taking different positions in a variety of asset types. Excessively homogeneous, or insufficiently diversified, strategies produce the poorest results, both in times of market growth and during crisis. In their drive towards achieving absolute return and minimizing risk associated with their portfolios, other types of investment funds that emulate the activity of HFs should focus particularly on strategies categorized as directional, event-driven, and hybrid, while avoiding or limiting activity based on non-directional strategies.

When evaluating the performance of HFs one 
Table 7. Performance Measures for HF Investment Strategies During the Financial Crisis (2007-2009)

\begin{tabular}{|c|c|c|c|c|c|c|c|c|c|c|c|c|}
\hline & 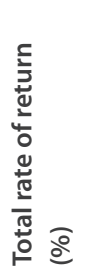 & 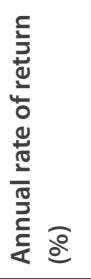 & 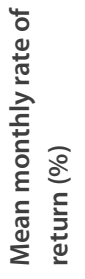 & 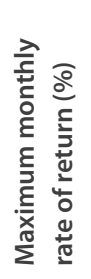 & 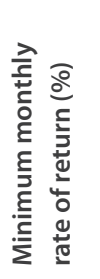 & 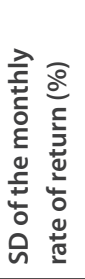 & $\stackrel{乛}{\mathscr{D}}$ & 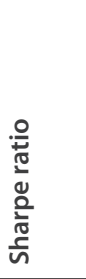 & 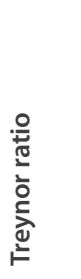 & 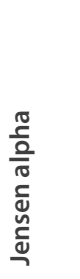 & 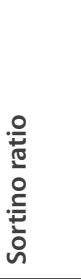 & $\frac{\mathfrak{a}}{0}$ \\
\hline 3M US T-Bills & 4.13 & 2.18 & 0.18 & 0.41 & 0.00 & 0.14 & - & 0.00 & - & - & - & 0.02 \\
\hline $\mathrm{MSCl}$ & -50.41 & -19.88 & -1.83 & 4.98 & -19.05 & 5.37 & 1.00 & -0.40 & -2.01 & - & - & 2.07 \\
\hline CSHFI & -1.44 & -2.40 & -0.02 & 3.16 & -6.55 & 2.25 & 0.29 & -0.09 & -0.69 & 0.38 & 0.30 & 0.73 \\
\hline \multicolumn{13}{|c|}{ DIRECTIONAL STRATEGIES } \\
\hline $\begin{array}{l}\text { Global } \\
\text { macro }\end{array}$ & 23.26 & 7.83 & 0.63 & 4.44 & -6.63 & 2.26 & 0.16 & 0.20 & 2.81 & 0.77 & 0.65 & 0.62 \\
\hline $\begin{array}{l}\text { Long/short } \\
\text { equity }\end{array}$ & -3.86 & -0.96 & -0.08 & 3.73 & -7.81 & 2.70 & 0.39 & -0.01 & -0.67 & 0.52 & 0.43 & 0.86 \\
\hline $\begin{array}{l}\text { Emerging } \\
\text { markets }\end{array}$ & -9.49 & -2.49 & -0.21 & 5.48 & -13.63 & 3.71 & 0.50 & -0.11 & -0.78 & 0.62 & 0.55 & 1.24 \\
\hline $\begin{array}{l}\text { Dedicated } \\
\text { short bias }\end{array}$ & 29.27 & 10.43 & 0.83 & 10.31 & -7.30 & 4.45 & 0.45 & 0.15 & 1.44 & -1.55 & -0.46 & 0.97 \\
\hline $\begin{array}{l}\text { Managed } \\
\text { futures }\end{array}$ & 29.26 & 9.90 & 0.79 & 6.61 & -4.79 & 3.20 & 0.03 & 0.19 & 20.3 & 0.67 & & 0.72 \\
\hline
\end{tabular}

NON-DIRECTIONAL STRATEGIES

\begin{tabular}{|c|c|c|c|c|c|c|c|c|c|c|c|c|}
\hline $\begin{array}{l}\text { Equity mar- } \\
\text { ket neutral }\end{array}$ & -33.20 & -9.41 & -0.82 & 2.02 & -40.45 & 6.91 & 0.31 & -0.14 & -3.23 & 0.38 & -0.47 & 2.77 \\
\hline $\begin{array}{l}\text { Fixed } \\
\text { income } \\
\text { arbitrage }\end{array}$ & -20.16 & -6.85 & -0.59 & 2.07 & -14.04 & 3.09 & 0.36 & -0.25 & -2.14 & 0.05 & -0.14 & 1.19 \\
\hline $\begin{array}{l}\text { Convertible } \\
\text { arbitrage }\end{array}$ & -16.96 & -5.50 & -0.47 & 5.72 & -12.59 & 3.43 & 0.37 & -0.19 & -1.76 & -0.09 & 0.00 & 1.27 \\
\hline
\end{tabular}


Table 7. Performance Measures for HF Investment Strategies During the Financial Crisis (2007-2009) (Continued)

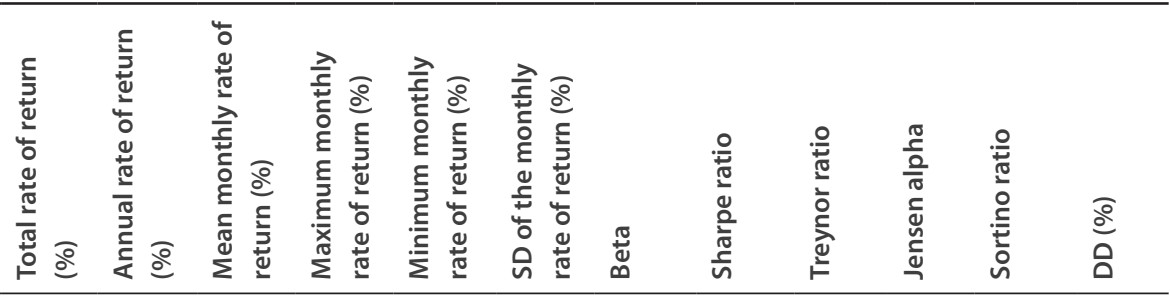

EVENT-DRIVEN STRATEGIES

$\begin{array}{lcccccccccccc}\begin{array}{l}\text { Distressed } \\ \text { securities }\end{array} & -5.91 & -1.79 & -0.15 & 2.65 & -5.66 & 2.02 & 0.26 & -0.16 & -1.27 & -0.19 & 0.08 & 0.68 \\ \begin{array}{l}\text { Event driven } \\ \text { 2.48 }\end{array} & 1.09 & 0.09 & 3.24 & -5.75 & 2.07 & 0.27 & -0.04 & -0.35 & 0.45 & 0.34 & 0.64 \\ \begin{array}{l}\text { Merger arbi- } \\ \text { trage }\end{array} & 11.44 & 3.91 & 0.32 & 3.22 & -3.49 & 1.33 & 0.16 & 0.11 & 0.88 & 0.46 & 0.35 & 0.33 \\ \end{array}$

HYBRID STRATEGIES

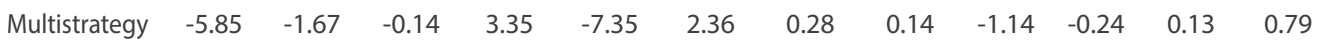

should always bear in mind that their operation primarily focuses on achieving absolute, rather than relative, return. This makes them market neutral. The key features of HFs, including large portfolio diversification, low variation of their asset values, and resistance against significant price drops, can be expected to continue to attract investors to alternative funds, which may contribute to the maintenance or increase of the funds' investment performance in the long term.

Overall, we may clearly state that HFs' active portfolio management and flexible investment policies guarantee not only achieving an absolute return, but also exceeding the performance of conventional asset types under any market conditions.

\section{References}

Agarwal, V., \& Naik, N. Y. (Sep., 2000). Multi-period performance persistence analysis of hedge funds. Journal of Financial and Quantitative Analysis, 35(3), 327-342.

Beber, A., \& Pagano, M. (Feb., 2013). Short-selling bans around the world: Evidence from the 2007-2009 crisis. The Journal of Finance, 68(1), 343-381.

Boyson, M., Stahel, C., \& Stulz, R. (2010). Hedge fund contagion and liquidity shocks. The Journal of Finance, 65(5), 1789-1816.

Brown, S. J., Goetzmann, W. N., \& Ibbotson, R. G. (Jan., 1999). Offshore hedge funds: Survival and performance. Journal of Business, 72(1), 91-117.

Brown, G. W., Green, J., \& Hand, J. R. (2012). Are hedge funds systemically important?. Journal of Derivatives, 20(2), 8-25.

Brunnermeier, K., \& Nagel, S. (2004). Hedge funds and the technology bubble. The Journal of Finance, 59(5), 2013-2040.

Cassar, G., \& Gerakos, J. (Aug., 2013). Does risk management work? Harvard Business School. Retrieved from https://www.hbs.edu/faculty/conferences/2014-imo/ Documents/Cassar\%20IMO\%202014.pdf (access: 10.05.2017).

Edelman, D., Fung, W., \& Hsieh, D. A. (Sept., 2013). Exploring uncharted territories of the hedge fund industry: Empirical characteristics of mega hedge fund firms. Journal of Financial Economics, 109(3), 734-758. Fung, W. K., \& Hsieh, D. A. (2006). Hedge funds: An in- 
dustry in its adolescence. Economic Review-Federal Reserve Bank Of Atlanta, 91(4), 1.

Getmansky, M., Lo, A. W., \& Makarov, I. (2004). An econometric analysis of serial correlation and illiquidity in hedge fund returns. Journal of Financial Economics, 74(3), 529-609.

Giraud, J. R., Hedges, J. R., \& Wright, T. (2001). Hedge funds: Economic benefits and practical challenges. The Journal of Alternative Investments, Winter, 4(3), 27-37.

Hedges IV, J. R. (2005). Hedges on hedge funds. How to successfully analyze and select an investment. John Wiley \& Sons.

Jaeger, R. A. (2003). All about hedge funds. The easy way to get started, The McGraw Hill Company.

Jagannathan, R., Malakhov, A., \& Novikov, D. (2010). Do hot hands exist among hedge fund managers? An empirical evaluation. The Journal of Finance, 65(1), 217255.

Jensen, M., C., (1968). Problems in selection of security portfolios. The performance of mutual funds in the period 1945-1964. The Journal of Finance, 23(2), 389-416

Joenväärä, J., Kosowski, R., \& Tolonen, P. (2012). New 'stylized facts' about hedge funds and database selection bias. EDHEC Working Paper, Retrieved from http://www.efmaefm.org/0efmameetings/ efma\%20annual\%20meetings/2013-Reading/papers/ EFMA2013_0410_fullpaper.pdf, (access: 20.05.2017).

Kosowski, R., Naik, N. Y., \& Teo, M. (2007). Do hedge funds deliver alpha? A Bayesian and bootstrap analysis. Journal of Financial Economics, 84(1), 229-264.

Lhabitant, F. S. (2006), Handbook of hedge funds, John Wiley \& Sons.

Liang, B. (2000). Hedge funds: The living and the dead. The Journal of Financial and Quantitative Analysis, 35(3), 309-326.

Marsh, I., \& Payne, R. (2010). Banning short sales and market quality: The U.K.'s experience. Cass Business School and Warwick Business School, London, Retrieved from http://ssrn.com/abstract=1645847, (access: 25.07.2017).

Nicholas, J. G. (2000). Market-neutral investing: Long/short hedge fund strategies. Bloomberg Press.

Perez, K., (2011). Wyniki inwestycyjne funduszy hedge. Czynniki wpływające na ich interpretację [Investment results of hedge funds. The factors affecting their interpretation]. Bank i Kredyt, 42(6), 85-124.

Schneeweis, T., \& Martin, G. (2001). The benefits of hedge funds: Asset allocation for the institutional investors. The Journal of Alternative Investments, Winter, 4(3), 7-26.

Sharpe, W. F. (Jan., 1966). Mutual fund performance. The Journal of Business, 39(1), Part 2, 119-138.
Sortino, F., van der Meer, R., (1991). Downside risk. The Journal of Portfolio Management, Summer, 17(4), 2731.

Stefanini, F., (2006). Investment strategies of hedge funds. John Wiley \& Sons, Ltd., West Sussex, England.

Treynor, J. L, (1965). How to rate management of investment funds. Harvard Business Review, 43(1), 63-75. 